\title{
Relato Final do VI Encontro do Fórum Nacional de Cursos de Geologia*
}

\author{
Rio de Janeiro (RJ), 30 de maio a 2 de junho de 2006
}

\author{
José Fernando Pina Assis ${ }^{1}$ (UFPA) \\ Lucia Fantinel (UFMG) \\ Celso Dal Ré Carneiro (Unicamp)
}

\section{INTRODUÇ̃̃o}

O VI Encontro do Fórum Nacional de Cursos de Geologia foi promovido entre os dias 30 de maio e 2 de junho de 2006, pelas seguintes universidades: Federal do Rio de Janeiro (UFRJ), Univ. Federal Rural do Rio de Janeiro (UFRRJ) e do Estado do Rio de Janeiro (UERJ) e pela Sociedade Brasileira de Geologia (SBGeo), nos institutos aos quais estão vinculados os cursos de Geologia das três instituições. Estiveram presentes os seguintes representantes:

1. Francisco Pinho (Univ. Federal de Mato Grosso/UFMT);

2. Ismar de Souza Carvalho (Univ. Federal do Rio de Janeiro/UFRJ);

3. Sérgio Citroni (Univ. Federal Rural do Rio de Janeiro/UFRRJ);

4. Beatriz Paschoal Duarte (Univ. do Estado do Rio de Janeiro/UERJ);

5. Lúcia Fantinel (Univ. Federal de Minas Gerais/UFMG);

6. Maria de Fátima Bitencourt (Univ Federal do Rio Grande do Sul/UFRGS);

7. Francisco Hilário Bezerra (Univ. Federal do Rio Grande do Norte/UFRN);

8. Roberto Mancini (Univ. Federal do Paraná/UFPR);

9. Fernando Pina (Univ. Federal do Pará/UFPA);

10. Valdecir Janaci (Univ. de São Paulo/USP);

\footnotetext{
* Este documento deve ser referido conforme abaixo:
}

Assis J.F.P., Fantinel L., Carneiro. C.D.R. 2008. Relato Final do VI Encontro do Fórum Nacional de Cursos de Geologia. Rio de Janeiro, maio-junho de 2006. Terræ Didatica, 4(1):67-77. <http:// www.ige. unicamp.br/ terraedidatica/>

1 Texto elaborado pelo Prof Fernando Pina (presidente do Fórum) a partir do registro diário das anotações feitas pelos vários coordenadores de seção do evento além das informações e citações fornecidas verbalmente pelos participantes do encontro.
11. Maurício Compiani (Univ. Estadual de Campinas/UNICAMP);

12. Washington B. Leite Júnior (Univ. do Estado de São Paulo/UNESP);

13. Luís Henrique Ronchi (Univ. do Vale do Rio dos Sinos/UNISINOS);

14. Messias Menezes (Univ. Federal de Ouro Preto/UFOP);

15. José Roberto Alecrim (Univ. Federal do Amazonas/UFA);

16. Luís Carlos Fontes (Univ. Federal de Sergipe/UFSE);

17. Paulo Cesar Boggiani (Lic. Geologia e Ciências Ambientais/USP).

O plenário totalizou a presença de 17 (dezessete) dos 23 (vinte e três) cursos das escolas de Geologia do Brasil, identificadas por suas respectivas coordenações, vice-coordenações e/ou representações indicadas. Também participaram coordenadores associados, diretores de unidades, docentes e estudantes dos Cursos de Geologia das três universidades patrocinadoras do evento. Estiveram ausentes os representantes dos Cursos de Geologia das Universidades Federais da Bahia, do Ceará e de Pernambuco.

Durante quatro dias foram colocadas em pauta questões que afetam a operacionalização e o desempenho acadêmico dos cursos de Geologia do país, cujos resultados estão sintetizados neste relato, elaborado a partir dos dados coletados pelo presidente do Fórum. 
Alguns trechos são citações literais dos palestrantes e/ou autores de trabalhos, enquanto outros foram obtidos a partir de informação prestada pelos demais participantes do encontro.

O encontro incluiu conferências, palestras, mesas redondas, visitas a instituições e empresas relacionadas às Ciências da Terra, além da participação da presidência na Mesa Redonda "As novas atribuições profissionais e os desafios da formação dos geólogos no Brasil " realizada no Clube de Engenharia do Rio de Janeiro em comemoração à passagem do Dia do Geólogo.

\section{TEMAS APRESENTADOS}

-Conferência

1. História do Ensino de Geologia no Brasil

2. Novas Tecnologias Educacionais com aplicação em Geociências

\section{-Palestras}

1. Como formar um geólogo?;

2. Reflexões sobre o ciclo básico em Geologia: devemos nos afastar da área tecnológica?;

3. Novas diretrizes para o Instituto Eschwege;

4. Programa de Cooperação entre IFES brasileiras e Universidades Portuguesas;

5. A Graduação em Geofísica na Univ. Federal Fluminense: panorama e perspectivas;

6. Novos cursos de Graduação em Geologia: o modelo da Universidade Federal de Sergipe (IFS);

7. O Programa de Recursos Humanos da Agência Nacional de Petróleo (ANP): contribuição para a formação dos geólogos brasileiros;

8. Difusão das Geociências: Projeto Caminhos Geológicos.

- Mesas Redondas

1. Perspectivas profissionais para o Geólogo;

2. Experiências educacionais no ensino de geologia;

3. Novas atribuições profissionais e os desafios da formação dos geólogos no Brasil.

-Visitas

1. Centro de Tecnologia Mineral (CETEM)

2. Centro de Pesquisas Leopoldo Miguez de Melo (CENPES/Petrobras)

-Excursão Pós-Encontro

1. Projeto Caminhos Geológicos: visita a afloramentos do Himalaia Brasileiro nas regiões de Cabo Frio e Búzios.

\section{0 de junho, Universidade Federal do Rio de Janeiro}

(UFRJ)

\section{ABERTURA DO ENCONTRO}

A cerimônia de abertura do encontro foi realizada no auditório do Centro de Ciências Matemáticas e da Natureza (CCMN) da UFRJ, com a formação de uma mesa plenária composta pelos professores: Ângela Rocha dos Santos (Decana do CCMN), Déia Maria Ferreira dos Santos (Superintendente Geral de Graduação), Josilda Rodrigues da Silva de Moura (Diretora do Instituto de Geociências), João Graciano Mendonça Filho (Chefe do Departamento de Geologia) além de José Fernando Pina Assis (Presidente do Fórum). Após os discursos iniciais e das boas-vindas, a mesa foi desfeita e o encontro teve continuidade com a apresentação dos temas do dia.

\section{ORDEM DO DIA}

\section{- Conferência}

\section{História do Ensino de Geologia no Brasil}

Conferencista - Prof. Dr. Messias Menezes (UFOP)

O autor apresentou um cenário histórico dos passos dados para a formação acadêmica do profissional geólogo no Brasil, desde a Fase Imperial com a criação da Escola de Minas de Ouro Preto, até o modelo das universidades atuais.

A figura central de sua exposição foi ClaudeHenry Gorceix (1842-1919) e o ensino das ciências geológicas na Escola de Minas de Ouro Preto, no crepúsculo do Império. Segundo o palestrante a pesquisa procurou: (a) verificar a importância de ter sido esse ensino localizado na Província de Minas Gerais, (b) entender como foi implantado na província, além de (c) buscar compreender o contexto dos sujeitos que constituíam as disciplinas geológicas e (d) investigar como o ensino da Mineralogia e da Geologia foi conduzido e praticado por diferentes atores na Escola de Minas de Ouro Preto (EMOP).

Segundo as pesquisas feitas pelo palestrante, a partir da década de 1870, emergiu no Brasil o ideal de República e também eclodiu um grande número de idéias novas. Nesta fase, fortaleceu-se entre os intelectuais brasileiros, o ideal de construção de uma identidade nacional, a afirmação de que o progresso e o desenvolvimento nacional aconteceriam pela ciência e técnica. A educação passa a ser concebida pelos reformadores como meio de transformar 
política e economicamente o país, tirando-o do atraso em que se encontrava, igualando-se às nações desenvolvidas.

Também foram destacados os principais aspectos da prática pedagógica de Henri Gorceix:

- Ênfase na experimentação e os trabalhos de campo;

- Aplicação das técnicas e métodos das aulas práticas das disciplinas geológicas, como estratégias de pesquisa para o avanço do conhecimento e para geração de riquezas.

O desafio de Gorceix foi desenvolver com os alunos a capacidade de reconstruir os conhecimentos científicos para que os mesmos se tornassem sujeitos ativos e participantes do processo de reconstrução econômica e social da Província das Minas Gerais. O ambiente educativo deveria ser também o lugar de construir conhecimento, possibilitando emergência do sujeito capaz de criticar. Olhada por esse ângulo, sua proposta educacional se entrelaça à concepção de ciência geológica. Gorceix procurou implantar um modelo técnico no Brasil, num momento em que a dimensão aplicada adquiria maior importância até mesmo em Paris, aproveitando que intelectuais brasileiros e franceses, demonstravam naquele momento uma profunda fé no conhecimento científico.

Finalizando, o palestrante destacou que o trabalho de Gorceix acabou sendo tomado como modelo para a construção nacional de um conhecimento aplicado, uma espécie de cartilha a ser seguida na busca do progresso econômico e moral.

\section{-Visita ao CENPES/Petrobras}

Realizada à tarde, logo no início dos trabalhos, a visita aos laboratórios e instalações do órgão incluiu palestra proferida por técnicos da empresa, que destacaram os setores principais de sua atuação: pesquisa, exploração e comercialização de Petróleo e seus derivados, além dos projetos para expansão das atividades da empresa.

-Palestras

Novas Tecnologias Educacionais com aplicação em Geociências

Conferencista - Prof. Dr. Hugo Fucks (PUC-RJ).

Apoiado no slogan "as sociedades do conhecimento", o autor apresentou um panorama das bases pedagógicas para utilização de novas ferramentas tecnológicas em geociências, enfatizando os seguintes binômios: informação X criticidade, interação X interatividade, informação X aprendizagem, comu- nicação X multimídia, educação X marketing.

\section{A Formação Acadêmica: reflexões sobre o Ciclo Básico}

Palestrante - Profa. Dra. Beatriz Paschoal Duarte (UERJ).

A autora discorreu sobre as principais questões levantadas pela maioria da comunidade: Geologia é uma ciência:

- Histórica - por entender o processo histórico da formação de uma região;

- Exata - porque os processos geológicos podem e devem ser quantificados;

- Aplicada - porque o uso dos dados, bem como sua interpretação, leva à solução de problemas específicos;

- Social - porque a aplicação direta do conhecimento geológico e a riqueza por ele gerada levam à melhoria do nível sócio-econômico das pessoas e das regiões onde é aplicado;

- Popular - porque isso não é verdadeiro no Brasil?;

- Relevante - sim, se considerarmos o tamanho de nosso país, os seus aspectos geológicos já conhecidos e o potencial de uso das informações geológicas já disponíveis;

- Lucrativa? - Bastaria apreciarmos os balanços das empresas mineradoras e da área do petróleo para afirmarmos que SIM!;

- Socialmente importante - considerando a penetração do desenvolvimento nas áreas onde há atividade mineral e as novas vertentes de aplicação do conhecimento geológico (meio ambiente, áreas urbanas, tecnologia mineral etc) fica evidente o viés social da geologia.

Segundo a palestrante, devemos considerar como investimento: a melhoria do ensino de geologia e das geociências; os programas de Levantamento Geológico Básico; as ações em Áreas Urbanas (Geotecnia); as ações de interferência na gestão do Meio Ambiente; a Atividade Econômica relativa ao Setor Mineral; a Atividade Econômica relativa à Indústria do Petróleo e Gás; a melhoria da qualidade de vida daqueles que se beneficiam diretamente da Atividade Econômica relativa aos setores Mineral e de Petróleo e Gás; a melhoria do perfil de gastos de órgãos estatais que levam em consideração o fator geologia na sua gestão.

No sentido de aprofundar a reflexão sobre a importância das ciências exatas para a geologia, a Profa. Beatriz Duarte lança duas perguntas ao plenário: 
1- Os processos geológicos precisam ser quantificados?

2- Os processos geológicos precisam ser modelados?

Após discorrer sobre essas questões e sua influência na concepção de Ciclo Básico dos cursos de Geologia, a Profa. conclui que o Geólogo deve ser conceitual e interpretativo, tecnológico e exato. Enfim, deve ser um profissional capaz de elaborar um modelo geológico e, ao mesmo tempo, testá-lo. Tarefa impossível se o intérprete não dominar os parâmetros físicos envolvidos.

Finalizando, a palestrante interroga: Por que afastar o geólogo da área tecnológica? A quem interessa? Por que formar geólogos menos bem-capacitados para o gerenciamento de grandes problemas relacionados à profissão? Será que não devemos analisar as atribuições futuras deste profissional?

A questão síntese para a reflexão de todos os envolvidos com a formação do geólogo foi assim formulada: será que o futuro profissional não precisará ser cada vez mais capacitado nas ciências fundamentais (básicas) para que possa atender às novas demandas que surgem?

-Mesa-Redonda

\section{Perspectivas profissionais para o Geólogo}

Debatedores - Fernando Pina (Pres. do Fórum), Ricardo Latgé Azevedo (APGRJ), Renato Silveira (SBGf), Paulo Amorim (Vale do Rio Doce), Mauro Becker (Petrobras), Nely Palermo (Sociedade Brasileira de Geologia).

Foram analisados vários aspectos relativos à absorção do profissional geólogo no mercado de trabalho. Desde sua formação acadêmica, passando pela necessidade de adequação ao perfil das empresas, chegando até às discussões sobre áreas promissoras para emprego e trabalho. Várias perguntas foram feitas, envolvendo o seguinte tema: estamos formando profissionais sintonizados e adequados?

Em uma pesquisa informal realizada com geólogos na faixa de 3 a 15 anos de profissão, as respostas foram:

- falta contato com a realidade de empresas, pois os conhecimentos teóricos nunca são aplicados;

- falta informação sobre a realidade profissional;

- falta segurança de trabalho e realidade social no interior;

- falta liberdade para "pensar”, pois o currículo é rígido.

As sugestões para melhorar esse quadro são:
- estágios em empresas, curriculares ou não;

- intercâmbio entre empresas e universidades;

- formação de banco de dados atualizado anualmente, com principais linhas de pesquisa, teses em andamento etc;

- fomentar a troca de conhecimento científico.

Foi consensual a necessidade de melhorar a formação do geólogo no que diz respeito ao domínio do uso de ferramentas imprescindíveis para aplicação do conhecimento, entre elas os conteúdos de Sistemas de Informação e Geoprocessamento. Houve, no entanto, divergência na definição do perfil do geólogo a ser formado: generalista ou especialista.

Considerando que as atividades do dia tomaram mais tempo do que o esperado, o plenário decidiu por unanimidade que não haveria a fase de debates sobre os temas apresentados.

\section{1 de maio de 2006 - Universidade Federal Rural do Rio de Janeiro (UFRRJ)}

O segundo dia de trabalho foi iniciado com uma visita às instalações do Centro de Tecnologia Mineral (CETEM). Em seguida os representantes dos cursos viajaram até o Campus da UFRRJ, no município de Seropédica, para dar prosseguimento às atividades do dia.

\section{ORDEM DO DIA}

\section{-Palestras}

O Papel do Cetem no Desenvolvimento da Tecnologia Mineral.

Palestrante - Dr. Adão Benvindo da Luz, Diretor do órgão.

Durante a apresentação foram destacados os diversos projetos desenvolvidos pelo CETEM e sua interação com instituições e o setor empresarial da área mineral. Após a palestra os coordenadores seguiram em visita monitorada às instalações do Centro. O palestrante destacou os seguintes pontos:

O papel do CETEM no desenvolvimento da tecnologia mineral: O CETEM desenvolve, cada vez mais, trabalhos de interesse da sociedade e com visibilidade para ser percebido por essa. $\mathrm{O}$ Centro alcançou, nos seus 28 anos de atividades ininterruptas, credibilidade e capacitação técnica para fazer frente aos desafios do setor mineiro e metalúrgico. Conta com excelente corpo técnico. Outro ponto forte do Centro é a sua infra estrutura 
laboratorial, muito adequada para a experimentação e o desenvolvimento de atividades de pesquisa. A capacitação técnica e laboratorial do CETEM está voltada para atendimento à pequena e média empresa de mineração, mas atende igualmente às grandes empresas do setor minero-metalúrgico.

Pequena mineração: O CETEM está atuando em quatro Arranjos Produtivos Locais (APLs) de Base Mineral: Aproveitamento Integral dos Pegmatitos do Nordeste; Opala de Pedro II-PI; Calcário Laminado do Cariri - CE e Pedra de Revestimento de Santo Antonio de Pádua - RJ.

Grandes empresas: Executa trabalhos de consultoria e Projetos de Pesquisa para: CVRD, Votorantim Metais, Petrobras, Alcoa, Mineração Caraíba, Fosfertil, Baterias Moura, dentre outras.

Plano Diretor do CETEM 2006-2010:

1. Recursos Humanos: Implementar ações junto ao Governo, fazer alianças com Empresas e Universidades, de forma a atender às demandas de RH do CETEM;

2. Recursos Financeiros para PD\&I: diversificar as fontes de captação, visando garantir recursos financeiros para execução de Projetos Estratégicos do CETEM;

3. Avanços em Tecnologia Mineral: acompanhar os avanços dos processos minero-metalúrgicos; identificar oportunidades em Tecnologias Emergentes (nanotecnologia, biotecnologia, modificação de minerais), e acreditar seus laboratórios de ensaios e processos;

4. Apoio Tecnológico com Tecnologias Limpas para Pequenas, Médias, Micro Empresas e APLs de Base Mineral;

5. Fortalecimento da Gestão: adotar práticas de gestão estratégica e promover a sua imagem externa;

6. Transferência de Tecnologia.

Estratégia de atuação: Criar um Núcleo de Inovação Tecnológica no CETEM e/ou associado a institutos congêneres, para disseminar e incentivar a Proteção Intelectual das inovações (Lei de Inovação); Atualização descentralizada do CETEM; meta: Implantar o Campus Avançado de Cachoeiro de Itapemirim (em andamento) e mais um na Região Nordeste (CETEM - Campus Avançado de Recife). Estabelecer pelo menos três Laboratórios "Associados" (desenvolvendo parceria duradoura), prioritariamente nas regiões Norte (Pará?), Sul (Santa Catarina?) e Centro Oeste (Goiás?).

A partir de 2006, o Centro alinhará o Plano Diretor às Macrodiretrizes do Plano Plurianual de Governo e o Planejamento Estratégico do MCT, que são: (1) Política Industrial, Tecnológica e de Comércio Exterior-PITCE. (2) Objetivos Estratégicos Nacionais (Amazônia), e (3) Ciência, Tecnologia e Inovação para a Inclusão Social (Centros Vocacionais, Nordeste e Semi-Árido, e Tecnologias Apropriadas). (4) Ciclo de Vida dos Materiais: Atentar para o uso integral dos materiais, bem como interação com os vários compartimentos (Biota). (5) Biotecnologia: Identificam-se duas grandes sub-áreas: (i) Estudar propriedades/ características de seletividade/especificidades de microorganismos para atuar em processos de natureza extrativa (bioxidação) e processo físico (bioflotação). (ii) Demanda por técnicas de tratabilidade biotecnológica, onde minérios, concentrados, resíduos e efluentes são testados quanto à sua potencialidade. (6) Valorização da Propriedade Intelectual face à acelerada busca por novos projetos e/ou processos que atendam especificações dos produtos e restrições de mercado. (7) Biomateriais: Aponta para materiais a partir de insumos minerais de alta pureza do tipo caulim, feldspato, buscando agregar valor. (8) Agromateriais: melhorar o aproveitamento dos recursos minerais, priorizando o desenvolvimento de processos que resultem em produtos passíveis de incorporação e/ou uso direto como insumos agrícolas.

Quem faz o CETEM? 88 Pesquisadores e Tecnologistas (88\% D.Sc.); 39 demais: Técnicos de Nível Médio, Administrativo e Analistas; 48 Bolsistas (PCI 31 e Agência de Fomento; 50 Bolsistas de Iniciação Científica; 35 Bolsistas de Pós-doutorado; 1 Bolsista de Aperfeiçoamento; 2 Pós-Graduação, M.Sc. e D.Sc. UFRJ, UFF, USP); 9 Estagiários (Nível Médio e Superior); 7 Terceirizados (Segurança, Limpeza, Oficina, Carpintaria).

No CETEM trabalham 45 Doutores e 19 Mestres.

Como o Centro divulga sua produção científica e tecnológica?: Publicação em Séries: Rochas e Minerais Industriais; Estudos e Documentos; Tecnologia Mineral; Tecnologia Ambiental; Gestão e Planejamento Ambiental; Inovação e Qualidade. Publicações Avulsas: Tratamento de Minérios - 4a Edição; Extração de Ouro; Rochas e Minerais Industriais: Usos e Especificações; Usinas de Beneficiamento de Minérios do Brasil. Eventos: Seminários, Congressos, Oficinas; e Periódicos: Nacionais e Internacionais. 
Preparação de Recursos Humanos: Curso de MBA em Rochas Ornamentais em Vitória-ES e no Rio de Janeiro - Fase de Planejamento. Curso de Tratamento de Minérios e Metalurgia para nível médio do CETEM - em andamento. Curso para nível médio em Angico dos Dias (Fase de planejamento). Curso sobre reologia de polpa - CADAM. Programa de Iniciação Científica para 36 Bolsistas. Programa de Capacitação Interna - PCI (31) para pesquisadores e técnicos de nível médio. Pós-Doutorado (UFBA, USP, UFOP). Aperfeiçoamento: Peru, Áustria, Equador (M.Sc.).

Cooperação Científica/Tecnológica, e Desafios da Tecnologia Mineral:

- Desenvolver modelos de simulação de moagem que permitam a redução do consumo de energia;

- Desenvolver processos que minimizem a formação de resíduos;

- Recuperar e reciclar a água no processo de processamento mineral;

- Minimizar a drenagem ácida nas minas de sulfeto;

- Utilizar reagentes biodegradáveis;

- Melhorar as tecnologias de aproveitamento de finos de minério;

- Desenvolver tecnologia para aproveitamento de pequenos depósitos de cobre (BA);

- Desenvolvimento de tecnologia para aproveitamento de bauxitas marginais da Amazônia (alto teor de sílica reativa);

- Desenvolver tecnologias apropriadas para aumentar a competitividade do setor de rochas ornamentais do País;

- Adaptação ou desenvolvimento de processo para aproveitamento de fosfato primário (Ex: Catalão, $\mathrm{GO})$;

- Desenvolver processos para aproveitamento das riquezas minerais do País, comprometidos com o desenvolvimento sustentável (Econômico, Social e Ambiental etc.).

Finalizando, o palestrante destacou que em seus 28 anos de atividade (completados em 18 abril/2006), o CETEM desenvolveu mais de 750 projetos de pesquisa voltados para melhoria e otimização de atividades minerárias.

\section{Como formar um Geólogo?}

Palestrante - Prof. Dr. Sérgio Citroni (UFRRJ).

O palestrante apresentou esquematicamente as fases de formação do geólogo na UFRRJ. Discutiu aspectos considerados bons e ruins nesse processo, argumentando sobre a necessidade de reequilibrar cargas horárias e conteúdos.

- O que é um geólogo? Cientista ou técnico? Ou as duas coisas? Segundo ele, é preciso responder a essas questões antes de decidir sacrificar algo dos conteúdos atualmente praticados ou, no sentido oposto, enriquecer ainda mais tais conteúdos.

- O que é a Universidade? Formadora de mão-deobra? Formadora de cérebros? Ou das duas coisas? Segundo ele a questão antecede a anterior.

Dependendo de como entendamos o que seja o profissional geólogo e de como entendamos a universidade, podemos até concluir que a universidade não é o lugar adequado para a formação do profissional, mas sim um curso técnico.

Ele finaliza com a seguinte afirmação: A formação rápida de profissionais e a ampliação de vagas são tendências que se anunciam. A visão de eficiência produtivista pode ser boa para uma empresa, mas a universidade não é uma empresa. Medir o desempenho de uma instituição de ensino em termos quantitativos é, muitas vezes, prejudicar a qualidade, desde que, evidentemente, não desejarmos abrir mão da formação crítico-criativa para fazer do universitário um simples leitor (e seguidor acrítico) de manuais.

\section{Novas diretrizes para o Instituto Eschwege}

Palestrante - Lucia Fantinel (UFMG).

A apresentadora discorreu sobre a trajetória e as perspectivas do Centro de Geologia Eschwege (CGE) no intuito de:

1. Informar sobre os contextos científico, educacional e social que condicionaram o surgimento e o desenvolvimento do CGE;

2. Recuperar a contribuição formativa dos estágios;

3. Informar sobre os nexos entre teoria e prática;

4. Revelar elementos balizadores das mudanças necessárias na estrutura e nas práticas do CGE.

O Instituto Eschwege (IE), precursor do CGE, foi criado em outubro de 1969, por meio de Ajuste Complementar ao Acordo Básico de Cooperação Técnica e Científica firmado entre Brasil e Alemanha. Idealizado pelo geólogo Reinhard Pflug, destinava-se a cumprir três funções principais: incentivar o intercâmbio entre professores e pesquisadores daqueles dois países; servir de apoio para as pesquisas de pós-graduandos; realizar cursos de mapeamento geológico para complementar a formação dos estudantes de geologia das universi- 
dades brasileiras. A designação Centro de Geologia Eschwege lhe foi atribuída em 1979, quando de sua incorporação ao Instituto de Geociências da UFMG. Os primeiros estágios de mapeamento geológico ocorreram em 1970 e estima-se em cerca de 7.300 o número de estudantes atendidos até o momento (2006).

A palestrante apresentou dados sobre a participação dos cursos no programa de estágios e sobre o universo de estudantes de Geologia que realizaram esses estágios a partir da criação do IE. Nesses trinta e seis anos de ensino de mapeamento geológico, foram oferecidas várias modalidades de estágios de campo, que convergiram para a forma atual, com as seguintes características:

1. Ensino centrado no estudante organizado em pequenos grupos: cada grupo de 3 estudantes (no máximo 4), preferencialmente de diferentes universidades, planeja e executa mapeamento 1:25.000 de uma área com cerca de $20 \mathrm{~km}^{2}$; resultando na produção de relatório, mapas e perfis geológicos;

2. Ensino-aprendizado que articula orientação e transmissão de conhecimentos pelo professor com aplicação e construção de conhecimentos pelo estudante;

3. Desenvolvimento de habilidades técnicas e de atitudes colaborativas;

4. Articulação teoria-prática: as atividades iniciais incluem pesquisa bibliográfica sobre a geologia da Serra do Espinhaço, uma aula expositiva e de campo sobre a geologia regional, organização dos grupos de trabalho e foto interpretação da área. As atividades de campo totalizam cerca de sete dias; atividades de gabinete e laboratório incluem, além de fotointerpretação, descrição petrográfica, análise de dados estruturais e petrográficos, elaboração de relatório, mapas e outras formas de representação de dados geológicos.

Assim, em 11 dias, os estudantes participam de um processo de aprendizado que é, ao mesmo tempo, treinador e investigativo.

A palestrante informou algumas medidas que estão sendo encaminhadas: preparação de arquivos com o conjunto de textos básicos sobre a geologia da Serra do Espinhaço Meridional para envio aos cursos de Geologia, antecipando o contato dos estudantes com essa bibliografia e a elaboração de síntese sobre a geologia regional; retomada dos estágios a partir de convênio entre a UFMG e o Ministério das Minas e Energia, cuja proposta foi apresentada no IV Encontro do Fórum, em Cuiabá, e levada à Secretaria de Geologia, Mineração e Transformação Mineral do MME por comissão constituída pelo coordenador do CGE e por representantes desse Fórum; participação de professores das escolas de origem no acompanhamento e/ou orientação dos estágios, ampliando o grupo de orientadores do IGC-UFMG.

Defendendo a necessidade de soluções de médio a longo alcance, que correspondam ao papel epistemológico e didático desses estágios de campo na formação do geólogo brasileiro, finalizou apresentando as perspectivas:

- Elaboração e execução de projetos que reforcem a matriz metodológica que deu sentido à criação e legitimação do CGE, em especial, a articulação ensino, pesquisa e extensão;

- Revitalização da infra-estrutura e das condições operacionais do CGE para garantir a oferta de estágios de mapeamento geológico e o apoio a iniciativas de cunho científico, profissional e de divulgação da geologia;

- Viabilizar a ampliação do grupo de orientadores por meio de contratação por projetos ou pela obtenção de bolsas para recém doutores;

- Viabilizar os Estágios Temáticos (Tópicos Especiais de Geologia de Campo) com temas anteriormente ofertados (Análise Estrutural, Análise de Bacias, Geologia, Mineralogia e Gemologia do Diamante) ou com novos temas que correspondam às potencialidades do IGC-UFMG e respondam aos interesses dos cursos de Geologia.

\section{1 de junho de 2006 - Universidade do Estado do Rio de Janeiro (UERJ)}

O terceiro dia do encontro foi realizado no auditório do Campus da UERJ.

\section{ORDEM DO DIA}

\section{-Palestras}

A implantação do Curso de Geologia na Univ. Federal de Sergipe

Palestrante - Luís Carlos Fontes (UFSE).

A palestra abordou os seguintes itens:

1. Origem da idéia;

2. Fundamentação da proposta;

3. Estratégia de abordagem (ataque);

4. Interação político-institucional;

5. Investimentos para implantação;

6. Organização: Núcleo de Pós-graduação, Grupo

de Geologia Sedimentar e Hidrogeologia, Grupo 
de Geologia Hidroambiental e do Quaternário e Grupo de Geologia Sedimentar e do Petróleo;

7. Base infraestrutural (parcerias: Petrobras, Unisinos);

8. Laboratórios (geoprocessamento, descrição de testemunhos, geologia ambiental e o convênio Petrobras-ANP/2006.

Preocupações levantadas pelo plenário:

1. Conhecimento concentrado em áreas dependentes de uma única fonte de financiamento;

2. Dependência do curso de pós-graduação;

3. Limitações para o a linha de formação do geólogo.

O Programa de Recursos Humanos da Agência Nacional de Petróleo (ANP) - contribuição para a formação dos geólogos brasileiros

Palestrante - Geóloga Ana Cunha (ANP).

A palestrante realizou apresentação das principais características do Programa de Recursos Humanos mantido pela Agência Nacional de Petróleo (ANP), procurando destacar seu potencial de contribuição para melhorar e complementar a formação dos geólogos brasileiros.

\section{Projeto Caminhos Geológicos: Educação em Geociências $\mathrm{RJ})$ \\ Palestrante - Kátia Mansur (geóloga da DRM/}

A palestrante iniciou sua fala destacando o fato de que o Rio de Janeiro é um estado com enorme potencial geológico e fundamentou suas idéias centrais que levaram à proposta de criação do projeto:

- ampliação da divulgação das geociências junto ao público leigo;

- criação de parques e sítios geológico-geomorfológicos;

- difusão do conhecimento sobre o patrimônio geológico do Rio de Janeiro.

Em seguida discorreu sobre diversos aspectos de um patrimônio geológico, que são afloramentos únicos, formações geológicas, estilos de deformação etc., de indubitável valor científico e ocorrência restrita, mostrando que são exemplos didáticos, testemunhos da história geológica, sendo necessária a difusão do conhecimento e a conscientização da sociedade em geral para sua preservação e entendimento da sua importância. O Projeto Caminhos Geológicos foi inaugurado em 2001 pelo DRM-RJ; caracteriza-se como iniciativa pioneira no país no aspecto de sinalização geológica sistemática de todo um Estado, e se materializa por meio de painéis com a evolução dos monumentos geológicos, identificados como "Pontos de Interesse Geológico"-PIG.

Enumerou ainda, por meio de imagens, os registros de feições importantes do estado:

1. Patrimônio Sedimentar: Falésias da Praia Rasa variação do nível do mar; Paleolaguna da Reserva de Tauá, Pântano da Malhada, Cabo Frio; Presença de conchas - transgressão marinha (5.100 AP); Afloramentos da Bacia de Resende; APA do Pau Brasil - Dunas do Peró; Bacias de Campos e Santos - Petróleo;

2. Patrimônio Geomorfológico: Dedo de Deus (Teresópolis e Guapimirim); formação geológica do Cão Sentado (Nova Friburgo); Parque Nacional da Serra dos Órgãos; A história geológica da formação do Pão de Açúcar, do Corcovado e da Baía de Guanabara (Rio de Janeiro); Monumento Natural dos Costões Rochosos;

3. Patrimônio Geotectônico:"Himalaia Brasileiro" colisão continental com evidências em Búzios; APA do Pau Brasil;

4. Patrimônio Petrológico-Mineralógico: vulcões do estado (rochas alcalinas: Nova Iguaçu, Itatiaia, Morro de São João, entre outros); Vulcão de Nova Iguaçu: conflito com mineração - TAC e trilhas interpretativas / Tombamento - Geoparque;

5. Patrimônio Paleontológico/Arqueológico: pedreiras de calcários, Bacia Calcária de São José de Itaboraí; Parque Paleontológico de São José de Itaboraí; Lagoa Salgada - únicas ocorrências de estromatólitos carbonáticos de idade holocênica do Brasil, e provavelmente de toda a América do Sul;

6. Patrimônio Hidrogeológico: Fonte de Água Mineral Iodetada de Pádua;

7. Patrimônio Geoambiental/Geomineiro: Rio das Ostras

- Pseudomorfos de pseudoleucita. A partir daí a palestrante apresentou os aspectos práticos da idéia: elaboração de painéis auto-explicativos construídos com material resistente ao intemperismo e que contivessem resumida e ilustradamente a história evolutiva de um determinado local onde os citados patrimônios estivessem à mostra sem, no entanto, serem notados como tal.

A palestrante identificou as dificuldades iniciais do Projeto Caminhos Geológicos e a estratégias para superá-las. Em especial, a dificuldade de obter parcerias para bancar os custos iniciais da construção dos 54 painéis, além da distribuição e fixação em diversos locais de 20 municípios do estado. Inicialmente, conseguiu as parcerias de órgãos de 
turismo, FAPERJ, PROPERJ, FEEEMA/CPRM, SBG/RJ, ABAS, UFRJ, MUSEU NACIONAL, entre outras instituições. Após a implantação dos primeiros painéis, porém, o sucesso foi tão imediato que as prefeituras passaram a procurar o DRM oferecendo-se para financiar a implantação de painéis em seus municípios, o que aumentou a demanda pelo levantamento dos locais de possível registro de interesse geológico.

Outra dificuldade inicial, logo vencida com o apoio de colegas profissionais, foi o levantamento das informações de caráter técnico sobre os "patrimônios".

Finalizando, a palestrante disse que o Projeto possui cunho científico, cultural, educativo, turístico e ecológico. Científico e educativo porque leva ao cidadão informações antes restritas à academia numa linguagem acessível. Turístico e cultural porque chama a atenção para o território, a paisagem e sua evolução. Ecológico porque, pela disseminação dos conceitos geológicos, desperta no cidadão respeito pelos grandiosos esforços da natureza para construir a paisagem da qual desfrutamos. Na vertente educacional destaca-se o caso de São José de Ubá, onde foram desenvolvidos painéis com desenhos e textos de crianças do ensino fundamental. Com o projeto, a Ciência passa a estar acessível a todos, gastando-se, apenas, tempo para leitura. No aspecto Cultural é relevante a parceria estabelecida com o Instituto Estadual do Patrimônio Cultural-INEPAC, cujo entendimento da geologia como bem cultural do povo do lugar levou ao tombamento de duas áreas em Armação dos Búzios. Na vertente Ecológica destaca-se seu papel como indutor do sentimento de preservação do Patrimônio Geológico, comprovado pelas solicitações de sinalização de sítios com interesse em sua preservação (Ex.: Reserva de Tauá, Cabo Frio). Dunas e APPs. Espera-se, a longo prazo, a educação das novas gerações para a preservação ambiental do planeta e para o conhecimento científico.

O Curso de Graduação em Geofísica no Instituto de Geociências da Universidade Federal Fluminense.

Palestrante - Profa. Dra. Eliane Costa (UFF).

A palestrante foi convidada pela organização do encontro a apresentar um histórico desde a criação até o momento atual do curso de formação de geofísicos daquela instituição.

Segundo ela os princípios que nortearam a criação foram:

1. Atenção à vocação do Estado do Rio e do País, tanto em exploração quanto na questão ambiental;

2. Instrumentalização do patrimônio de 30 anos do LAGEMAR em Geofísica Marinha.

A partir dessas premissas ela passou a discorrer sobre o projeto em si.

Por que Geofisica? Idade média dos profissionais; demandas sociais recentes no Estado do Rio; tradição do departamento; necessidade de criar massa crítica na área.

Qual o Perfil pretendido? Base sólida em Geologia, Física, Cálculo e Métodos Numéricos; profissional criativo e com habilidades multidisciplinares; espírito de equipe.

Em seguida apresentou as características pedagógicas do curso:

1. Duração de cinco anos (10 semestres); entrada anual de 20 alunos;

2. Carga horária total de $5054 \mathrm{~h}$.

3. Habilitações: Bacharelado em Exploração Marinha e Exploração Ambiental.

Grade curricular: Geomorfologia I, Matemática III, Programação de Computadores III, Geometria Analítica e Cálculo Vetorial, Sistema Terra I e II, Oceanografia, Matemática IV, Estatística V, Física I, Física Experimental I, Geologia Sedimentar, Fundamentos de Mineralogia e Petrologia, Geologia Marinha, Cartografia, Física II, Física Experimental II, Estratigrafia, Geologia Estrutural, Mapeamento Geológico, Topografia XI, Geoprocessamento I, Introdução aos Métodos Numéricos, Física III, Física Experimental III, Métodos Acústicos - Princípios e Métodos, Métodos Elétricos e Eletromagnéticos, Tratamento de Dados Geofísicos, Navegação e Posicionamento, Prática de Campo I, Geologia do Petróleo, Poluição Marinha. Gravimetria e Geomagnetismo, Sísmica de Reflexão e Sismoestratigrafia, Processamento Digital de Sinais, Prática de Campo II, Perfilagem Geofísica de Poço, Morfodinâmica Costeira; Optativa 1. Métodos Potenciais de Prospecção Geofísica, Geofísica Nuclear, Geoestatística, Prática de Campo III, Proces. Sísmico, Geofísica aplicada a Problemas Ambientais, Atividade Acadêmica Curricular I; Optativa 2. Geotectônica, Geotermia, Prática de Campo IV, Atividade Acadêmica Curricular I; Optativa 3. Estágio Curricular I, Projeto Final em Geofísica de Exploração I, Atividade Acadêmica Curricular III; Optativa 4. Estágio Curricular 
I, Projeto Final em Geofísica de Exploração II, Atividade Acadêmica Curricular IV; Optativa 5.

Após a apresentação foram levantadas muitas questões pelo plenário manifestando opinião sobre o curso apresentado, entre as quais se destacam as seguintes preocupações:

1. Elevada carga horária total do curso, ultrapassando as 5.000h;

2. Elevada carga horária de matérias de conteúdo matemático;

3. Dispersão do conteúdo de cunho geológico, distanciando o graduando das informações sobre a origem dos fenômenos a serem estudados pela geofísica;

4. Prejuízo do graduando no que diz respeito ao avanço do seu conhecimento integrado.

\section{Debate}

A sessão do dia foi encerrada com um debate sobre dois temas:

1. Escolha da sede para o próximo encontro do Fórum (2007) - foram sugeridas as candidaturas de São Paulo, Porto Alegre e Ouro Preto. As diversas tentativas de escolha não resultaram em decisão de maioria e por isso o assunto foi transferido para o encontro do Fórum durante o Congresso Brasileiro de Geologia a ser realizado em Aracaju em setembro de 2006;

2. Eleição para a presidência e vicepresidência do Fórum, - o único nome indicado foi o da Profa. Lucia Fantinel da UFMG, porém a despeito de único e considerando que a mesma não estava mais presente no encontro, decidiu-se pelo adiamento da escolha até que fosse feita uma consulta à indicada.

Ao final do debate o plenário elaborou e aprovou o documento "Carta do Rio de Janeiro" transcrito abaixo (na íntegra), que foi lido no Clube de Engenharia durante a sessão de comemoração pela passagem do Dia do Geólogo.

\section{DECLARAÇÃO DO RIO DE JANEIRO}

O VI Encontro do Fórum Nacional de Cursos de Geologia, realizado de 31 de maio a 2 de junho de 2006, na cidade do Rio de Janeiro-RJ, reafirma mais uma vez importância da atuação do geólogo para o desenvolvimento econômico e social de nosso país. Em função da relevância das Instituições de Ensino Superior para a formação profissional adequada e integrada à realidade social brasileira, considera que:

1. O tempo de duração e o conteúdo programático dos cursos de graduação em Geologia devem ser apropriados ao ensino pela pesquisa para a formação do geólogo cidadão, crítico, científica e tecnologicamente capacitado para atender com qualidade às demandas da sociedade;

2. O aquecimento e a expansão do mercado de trabalho para o geólogo são realidades nas quais a criação e implantação de novos cursos requerem reflexão e envolvimento da comunidade geológica. Deve ser garantida a qualidade da formação dos geólogos, independente de demandas específicas de mercado;

3. É fundamental garantir a qualidade dos Cursos de Graduação em Geologia já existentes, por meio de programas que visem a imediata recuperação de toda a infra-estrutura física e de pessoal das instituições superiores de ensino, permitindo a melhoria do ensino oferecido e a ampliação do número de vagas docentes e discentes;

4. A continuidade dos estágios de Geologia de Campo no Centro de Geologia Eschwege, em Diamantina-MG, pressupõe aporte de recursos financeiros e ampliação do grupo de orientadores, inclusive com a formação de novos professores de mapeamento geológico para atender ao programa de prática de campo e à oferta de novos estágios temáticos.

Ao concluir os trabalhos, o Fórum entende que os novos desafios impostos e as soluções mais adequadas para o desenvolvimento social e econômico brasileiro relacionam-se, em causa e efeito, com a formação profissional de qualidade dos geólogos, cumprindo-se assim a função fundamental da Universidade - a construção da cidadania.

Rio de Janeiro, 02 de junho de 2006

Assinaram o documento:

Beatriz Paschoal Duarte - Universidade do Estado do Rio de Janeiro-UERJ;

Fernando Pina - Universidade Federal do ParáUFPA;

Francisco Hilário Bezerra - Universidade Federal do Rio Grande do Norte-UFRN;

Francisco Pinho - Universidade Federal de Mato Grosso-UFMT;

Ismar de Souza Carvalho - Universidade Federal do Rio de Janeiro-UFRJ;

Luís Henrique Ronchi - Universidade do Vale do Rio dos Sinos-Unisinos; 
Lucia Fantinel - Universidade Federal de Minas Gerais-UFMG;

Fenando Mancini - Universidade Federal do ParanáUFPR;

Maurício Compiani - Universidade Estadual de Campinas-Unicamp;

Maria de Fátima Bittencourt - Universidade Federal do Rio Grande do Sul-UFRGS;

Messias Gilmar de Meneses - Universidade Federal de Ouro Preto-UFOP;

Paulo Boggiani- Universidade de São Paulo-USP; Sérgio Citroni - Universidade Federal Rural do Rio de Janeiro-UFRRJ;

Valdecir Janasi - Universidade de São Paulo-USP;

Washington Leite - Universidade do Estado de São Paulo-UNESP.

\section{Comemorações do Dia do Geólogo}

O final da agenda oficial do VI Encontro do Fórum foi comemorado com a participação dos membros presentes ao encontro em sessão plenária realizada no Clube de Engenharia do Rio de Janeiro comemorativa da passagem do Dia do Geólogo. A sessão, sob o tema central: "As Novas Atribuições Profissionais e os Desafios da Formação dos Geólogos no Brasil, foi realizada na noite do mesmo dia do encerramento do encontro do Fórum, e permitiu uma noite de congraçamento e descontração.

Coube à presidência a honra de participar da Mesa Diretora da Sessão em companhia dos seguintes membros: Engenheiro Raimundo Oliveira (Presidente do Clube de Engenharia), Engenheiro Cláudio Amaral (Presidente da ABGE), Engenheiro Marcos Túlio (Presidente do CONFEA), Geólogo Nivaldo Bosio (Presidente da FEBRAGEO), Geólogo Ricardo Latgé Milward de Azevedo (Presidente da APG-RJ) e Geólogo Rômulo Machado (Presidente da SGB).

\section{2 de junho de 2007 - Excursão pelos Caminhos Geológicos}

O último dia do encontro do Rio de Janeiro foi ocupado com a viagem a campo monitorada pela geóloga Renata Schimidt (UERJ) uma das coordenadoras do projeto Caminhos Geológicos. Os coordenadores visitaram locais registrados como Patrimônio Geológico do Estado do Rio, onde estão afixados os painéis descritivos do projeto Caminhos Geológicos. Na seguinte ordem:
Ponto 1. Forte São Mateus (Cabo Frio) - ortoanfibolitos e ortognaisses paleoproterozóicos com 2,0 Ga;

Ponto 2. Orla Bardot (Búzios) - história geológica do Himalaia Brasileiro;

Ponto 3. Lagoinhas (Búzios) - evento colisional cambriano com $525 \mathrm{Ma}$;

Ponto 4. Ponta do Marisco (Búzios) - basaltos e diques de diabásio formados durante eventos tectônicos mesozóico-cenozóicos associados ao rifteamento e abertura do Oceano Atlântico.

Durante a viagem de retorno, os coordenadores presentes discutiram o tema Eleição do Fórum. O único nome indicado para a Presidência do Fórum foi o da Profa. Lucia Fantinel da UFMG, porém a despeito de único e considerando que a mesma não estava mais presente no encontro, decidiu-se pelo adiamento da escolha até que fosse feita uma consulta à indicada.

\section{ENCERRAMENTO}

Em nome da Presidência do Fórum o Prof. Fernando Pina finalizou o encontro externando esperanças de que tenha sido possível, definitivamente, fazer do Fórum uma instância efetiva e formal de acompanhamento do ensino de Geologia no país. Elogiou o espírito de equipe que caracterizou o trabalho dos participantes e palestrantes, estimulando o debate e o intercâmbio de experiências para fortalecimento dos cursos de graduação em Geologia das diversas universidades brasileiras.

Destacou o esforço dos participantes (professores, estudantes e pessoal de apoio logístico e material) para com o sucesso do encontro. Agradeceu a acolhida maravilhosa recebida por todos os participantes do encontro, pelas pessoas envolvidas com a organização tripartite das universidades, nomeadamente os professores Ismar Carvalho (UFRJ), Sérgio Citroni (UFRRJ) e Beatriz Paschoal Duarte (UERJ) que, num esforço enorme, deram ao encontro um aspecto bem humorado, sem nunca perder a seriedade e dedicação. Por fim estendeu agradecimentos à Universidade Federal do Rio de Janeiro (UFRJ), Universidade Federal Rural do Rio de Janeiro (UFRRJ) e Universidade do Estado do Rio de Janeiro (UERJ) representadas pelos membros das direções de seus Institutos de Ciências Exatas e da Terra, pelo brilhantismo e presteza com que organizaram e sediaram o evento. 